\title{
Ameliyathane Hemşirelerinde Aleksitimi Düzeyi ve İletişim Becerilerine Etkisi: Doğu Karadeniz Örneği
}

\author{
Alexithymia Level in Operating Room Nurses and Their Effect on Communication Skills: The Case of Eastern \\ Black Sea
}

\author{
Demet KARAİSMAİLOĞLU ${ }^{1}$, Nurşen KULAKAÇ², Dilek ÇİLİNGİR ${ }^{3}$
}

\begin{abstract}
ÖZ
Bu çalışma ameliyathane hemşirelerinde aleksitimi düzeyinin belirlenmesi ve iletişim becerilerine olan etkisinin değerlendirilmesi amacıyla yapıldı. Kesitsel türde yapılan araştırma, Haziran-Aralık 2019 tarihlerinde Türkiye'nin Doğu Karadeniz Bölgesinde bulunan üç hastanede gerçekleştirildi. Araştırmaya katılan 101 ameliyathane hemşiresi araştırmanın örneklemini oluşturdu. Araştırmanın verileri Sosyodemografik bilgi formu, Toronto Aleksitimi Ölçeği (TAÖ-20) ve İletişim Becerileri ÖlçeğiYetişkin Formu (İBÖ-YF) kullanılarak toplandı. Verilerin analizinde SPSS 23 paket programı kullanıldı. Araştırmaya katılan hemşirelerin yaş ortalaması $35.73 \pm 7.35$ ve $\% 73.3$ 'ü kadındır. Hemşirelerin \%84.2'sinin aleksitimiyi daha önce duymadığ1 ve \%69.3'ünün iletişim becerileri ile ilgili eğitim almadığı belirlendi. Hemşirelerin orta derecede aleksitimik oldukları ve aleksitimi puanları ile iletişim becerileri puanları arasında negatif yönde orta düzeyde anlamlı bir ilişkinin olduğu görüldü (r:-0.48, $\mathrm{p}=0.04$ ). Ameliyathane hemşirelerinin aleksitimi konusundaki farkındalıklarının arttırılması ve iletişim becerilerinin güçlendirilmesi gerektiği sonucuna varılmıştır. $\mathrm{Bu}$ konulara ilişkin eğitimlerin düzenlenmesi ile hemşirelerin hasta ve ekip üyeleri ile olan iletişiminin etkili bir şekilde sürdürülmesi sağlanabilir.
\end{abstract}

Anahtar Kelimeler: Aleksitimi, Ameliyathane, Hemşire, İletişim

\begin{abstract}
This study was conducted to determine the level of alexithymia in operating room nurses and to evaluate its effect on communication skills. A cross-sectional research conducted in East Black Sea Region of Turkey was held in June-December 2019 in three hospitals in the area. 101 operating room nurses participating in the study constituted the sample of the study. Personal Information Form, Toronto Alexithymia Scale (TAS-20) and Communication Skills Scale-Adult Form (IAS-SF) were collected. SPSS 23 package program was used in the analysis of the data. The average age of the nurses in the study is $35.73 \pm 7.35$ and $73.3 \%$ are women. It was determined that $84.2 \%$ of the nurses had not heard of alexithymia before and $69.3 \%$ did not receive training on communication skills. It was found that the nurses were moderately alexithymic and there was a negative correlation between their alexithymia scores and communication skills scores $(\mathrm{r}:-0.48, \mathrm{p}=0.04)$. The relevant conclusion was reached to increase the awareness of operating room nurses with unknown alexithymia and to complete their communication skills. By organizing trainings on these issues, it can be ensured that the communication of nurses with patients and team members is maintained effectively.
\end{abstract}

Keywords: Alexithymia, Operating Room, Nurse, Communication

${ }^{1}$ Arş. Gör., Demet KARAİSMAİLOĞLU, Cerrahi Hastalıkları Hemşireliği, Karadeniz Teknik Üniversitesi Sağlık Bilimleri Fakültesi, demetk@windowslive.com, ORCID: 0000-0002-1617-4078

${ }^{2}$ Öğr. Gör., Nurşen KULAKAÇ, Cerrahi Hastalıkları Hemşireliği, Gümüşhane Üniversitesi Sağlık Bilimleri Fakültesi, nrsnklkc@gmail.com, ORCID: 0000-0002-5427-1063

${ }^{3}$ Prof. Dr., Dilek ÇİLINGİR, Cerrahi Hastalıkları Hemşireliği, Karadeniz Teknik Üniversitesi Sağlık Bilimleri Fakültesi, dilekcilingir1@yahoo.com, ORCID: 0000-0002-0660-8426 


\section{GIIRIŞ}

Aleksitimi kavramı "Duygular için söz yokluğu" olarak tanımlanmış ve ilk olarak Sifneos tarafindan psikosomatik hastalarda görülen belirtileri ifade etmek amaciyla kullanılmıştır. Günümüzde ise aleksitimi, sadece psikosomatik hastalıkları kapsamayıp diğer birçok psikolojik ve fizyolojik hastalıkları da içine alan ve özellikle sağlıklı bireylerde de incelenen bir kavram haline gelmiştir. ${ }^{1}$ Aleksitimi, bireyin kendi iç dünyasındaki hissiyatı anlamlandırma ve ifade etmede yaşadığı zorluk, fizyolojik sorunlar1 somatik duygulardan ayırt edememe, hayal etme yeteneğinin sinırlı olması ve çevresel uyaranların etkin olduğu bilişsel süreç ile karakterizedir. ${ }^{2}$ Bireyin duygularını tanımaması onun olaylar karşısında gerekli tepkiyi verememesine bu da çevresi tarafından duygusuz, donuk, soğuk ve mesafeli algılanmasına neden olmaktadır. Yaşanan içsel sıkıntıların söze dökülememesi nedeniyle birey bu duyguları somatize ederek bedensel yakınmalar şeklinde dışa vurmaktadır. Hayal gücündeki kısitlılıklar bireyin tekdüze, işlemsel ve fazla gerçekçi düşler ortaya koymasında rol oynamaktadır. Kendi iç dünyalarına olan yabancılıkları onların dişa dönük kişilik sergilemesine ve davranışlarında diş uyaranların etkili olmasına neden olmaktadır. ${ }^{3}$

Aleksitimik bireylerin kendi duygusal süreçlerinin yanı sıra başkalarının duygularını anlama ve onlarla empati kurabilme becerisi yönünden de oldukça kısıtlı oldukları belirtilmektedir. Bireyin duygularını tam olarak yaşayamaması ve çevresiyle olan duygusal etkileşiminin sınırlı olması kişinin iletişim becerilerini de önemli ölçüde etkilemektedir. Kişilerarası ilişkilerde uyum sağlamaya çalıştıkları için doğallıktan uzak şekilde ve kendi kişiliklerini gizleyerek iletişimlerini sürdürmektedirler. ${ }^{4}$ İletişimin doğal sürecindeki duygu paylaşımını deneyimleyemeyen aleksitimik bireyler zamanla uyum göstermekten uzaklaşıp kendi içine çekilmekte ve yalnızlaşmaktadır. Sosyal yönüyle insanın yaşamsal motivasyonunda çevresiyle olan iletişimi yadsınamaz bir gerçektir. Hem kendi iç dünyasına hem de yaşadığ 1 dış dünyaya karşı derin bir anlamsızlık içinde olan aleksitimik bireylerde, ilerleyen süreçte anksiyete, depresyon, kronik ağrı ve yeme bozuklukları gibi birçok hastalık görülebilmektedir. ${ }^{5}$

Günümüzde aleksitimi birçok meslek grubunda araştırılan bir kavram olarak yer almaktadır. Özellikle kişilerarası etkileşimin ön planda olduğu hemşirelik mesleğinde duyguları anlama ve aktarma, empati kurma ve iletişim becerileri önem taşımaktadır. Bakım sürecinde hastanın duygularının anlaşılması ve ihtiyaçlarına yönelik duyarlı olunması hemşirelik bakımının etkili yürütülmesi açısından elzemdir. Diğer yandan hemşireliğin ekip anlayış1 çerçevesinde gerçekleşmesi iletişimin ne kadar önemli olduğunu bir kez daha vurgulamaktadir. ${ }^{6} \quad$ Ameliyathane hemşirelerinin ekip çalışmasının aktif şekilde yürütüldüğü, sürekli dikkat gerektiren, uzun süreler ayakta kalınan, uykusuzluğun ve yorgunluğun hakim olduğu stresli çalışma ortamına sahip olması, ameliyat sürecinde görülen birçok türde vakanın bireyin duygusal anlamda duyarsızlaşmasına neden olması ve vardiyalı çalışma saatlerinden ötürü sosyalleșmenin az olması nedeniyle aleksitimi açısından değerlendirilmesi gerektiği düşünülmektedir. ${ }^{7}$ Hemşirelerin empati ve iletişim becerileri ile ilgili yapılmıș birçok çalıșma olmasına karşın ameliyathane hemşirelerinde aleksitimi düzeyi ve iletişim becerilerine olan etkisini inceleyen bir çalışma bulunmamaktadır. ${ }^{8-11} \mathrm{Bu}$ çalışma ile ameliyathane hemşirelerinin aleksitimi düzeylerinin belirlenmesi ve iletişim becerilerine olan etkisinin değerlendirilmesi amaçlanmaktadir. 


\section{MATERYAL VE METOT}

\section{Araştırmanın Tipi}

$\mathrm{Bu}$ çalışma kesitsel ve tanımlayıcı tipte bir araştırmadır.

\section{Araştırmanın Evren ve Örneklemi}

Çalışmanın verileri Haziran-Aralık 2019 tarihlerinde toplandı. Araştırmanın evrenini Türkiye'nin Doğu Karadeniz Bölgesi'nde bulunan üç hastanenin ameliyathanelerinde çalışan hemşireler, örneklemi ise evreni bilinen örneklem hesaplama formülü kullanılarak belirlenen 113 hemşire oluşturdu. Çalışmaya katılmaya gönüllü olan ve formları eksiksiz dolduran 101 hemşire ile araștırma tamamlandı.

\section{Veri Toplama Araçları}

Çalışmanın verileri Sosyodemografik bilgi formu, Toronto Aleksitimi Ölçeği (TAÖ-20) ve İletişim Becerileri Ölçeği-Yetişkin Formu (İBÖ-YF) kullanılarak yüz yüze görüşme tekniği ile toplandi.

Araştırmacılar tarafından hazırlanan sosyodemografik bilgi formu, çalışmaya katılan hemşirelerin cinsiyet, yaş, eğitim düzeyi, yaşadığı yer, sigara kullanma durumu gibi kişisel bilgilerini içeren 15 sorudan oluşmaktadır.

Toronto Aleksitimi Ölçeği (TAÖ-20); Bagby ve ark. tarafından geliştirilen ölçek Güleç ve ark. (2009) tarafından Türkçeye uyarlanmıştır. ${ }^{12,13}$ Likert tipte olan ölçek, 20 maddeden oluşmakta ve 1-5 aras1 puanlanarak değerlendirilmektedir. Ölçek toplam puanı 20-100 arasındadır. Yüksek puanlar yüksek aleksitimik seviyeyi göstermektedir. Ölçeğin bu araştırma için Cronbach alfa katsayısı 0,89 olarak bulunmuştur.

İletişim Becerileri Ölçeği-Yetişkin Formu (İBÖ-YF), Türkçe uyarlaması, Korkut Owen ve Demirbaş-Çelik tarafından 2017 yılında yapılmıştır. Ölçek; 1-5 arası puanlanan ve 25 maddeden oluşan likert tipi bir ölçektir. Ölçekten alınan yüksek puan bireyin iletişim becerilerinin gelişmiş olduğu yönünde değerlendirilmektedir. ${ }^{14}$ Ölçeğin bu araştırmada Cronbach alfa güvenilirlik katsayısı 0,92 olarak bulunmuştur.

\section{Verilerin Değerlendirilmesi}

Araştırmada verilerin analizinde SPSS 23.0 programı kullanıldı. Sayı ve yüzdelik hesapları, aritmetik ortalama gibi tanımlayıc1 analizlerin yanı sıra normal dağılım gösteren gruplar arası değişkenlerin karşılaştırılmasında $\mathrm{t}$ testi, One-Way ANOVA; sayısal değişkenler arasındaki ilişki ise Pearson korelasyon analizi ile değerlendirildi. İstatistiksel anlamlılık $\mathrm{p}<0.05$ düzeyinde kabul edildi.

\section{Araştırmanın Etik Yönü}

Çalışmanın yapılabilmesi için ilgili Üniversitenin Etik Kurulu'ndan gerekli onay (Karar No:2019/5) ve araştırmanın yürütüleceği hastane yönetiminden yazılı izin (No: 23618724-772.02; No:29330515604.01.01-495) alındiktan sonra ameliyathanede çalışan hemşirelerden gönüllülük ilkesi doğrultusunda bilgilendirilmiş onam alındı. Ölçeklerin izin bilgisi elektronik posta yoluyla alındı. Bu çalışma Helsinki İlkeler Deklarasyonu'na uyularak gerçekleştirildi.

\section{Araştırmanın Kısıtlılıkları}

Veri toplama araçlarının uygulandığ tarihlerde ameliyathanede çalışan ve araştırmaya katılmayı kabul eden hemşirelerden elde edilen verilerle sinırlı olan araștırma, sadece araștırmanın yapıldığ 1 hastanelerdeki ameliyathane hemşirelerine genellenebilir.

\section{BULGULAR VE TARTIŞMA}

Çalışmaya katılan hemşirelerin yaş ortalamas1 35,73 $\pm 7,35$ (min.24; max.58) olup $\% 73,3$ 'ü kadındır. Hemşirelerin \%83,2'sinin evli, \%62,4'ünün üniversite mezunu, \%44,6'sının eğitim araştırma hastanesinde çalıştığ1, \%85,1'inin ailesi ile birlikte yaşadığı, \%86,1'inin kronik hastalığının olmadığı, \%79,2'sinin sigara içmediği ve 
\%97'sinin alkol kullanmadığı belirlendi. Hemşirelerin ortalama çalışma süresinin $14,03 \pm 8,05$ yıl, ameliyathanede çalışma

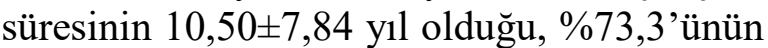
mesleği isteyerek seçtiği, \%84,2'sinin aleksitimiyi daha önce duymadığ 1 ve \%69,3'ünün iletişim becerileri ile ilgili eğitim almadığ

Araştırmaya katılan hemşirelerin cinsiyet, yaş, eğitim düzeyi, sigara içme durumu, kronik hastalık varlığ 1 , meslekte çalışma yılı ve mesleği isteyerek seçme durumu ile aleksitimi ve iletişim becerileri puanları arasında anlamlı bir ilişki bulunmadı $(p>0.05)$. Medeni duruma göre aleksitimi puanları karşılaştırıldığında, bekar hemşirelerin aleksitimi puanlarının anlamlı olarak daha yüksek olduğu saptandı. Medeni duruma göre hemşirelerin İBÖ puanları arasinda anlamlı bir farklilık bulunmadi. Hemşirelerin mezun oldukları okula göre İBÖ puanları arasında anlamlı bir fark olduğu saptandı $(\mathrm{p}<0,05)$. Farkın lisansüstü gruptan kaynaklandığı, lisansüstü mezunu hemşirelerin iletişim düzeylerinin diğer hemşirelerden daha yüksek olduğu belirlendi $(\mathrm{d}>\mathrm{c}=\mathrm{b}=\mathrm{a})$. Hemşirelerin iletişim becerileri ile ilgili eğitim alma durumlarına göre aleksitimi ve İBÖ puanları karşılaştırıldığında; eğitim alan hemşirelerin aleksitimi puanlarının anlamlı olarak düşük olduğu, iletişim puanlarının ise anlamlı olarak yüksek olduğu bulundu (Tablo 1). Hemşirelerin aleksitimi puan ortalaması $52,94 \pm 6,71$ olup, orta derecede aleksitimik oldukları, İBÖ puanlarının ise 98,09 $\pm 9,66$ olduğu saptandı. Hemşirelerin aleksitimi puanları ile iletişim becerileri puanları (r:$0,48, p=0,04)$ arasinda istatistiksel olarak negatif yönde anlamlı bir ilişkinin olduğu saptand1 (Tablo 2).

Aleksitimi kavramı hemşirelik alanında gün geçtikçe daha çok araştırılan bir konu haline gelmektedir. ${ }^{6}$ Ameliyathane hemşirelerinin aleksitimi düzeyleri ve iletişim becerilerine olan etkisinin araştırıldığı bu çalışmada; hemşirelerin cinsiyet, yaş, eğitim düzeyi, meslekte çalışma yılı ve mesleği isteyerek seçme durumu gibi özelliklerin aleksitimi ve iletişim becerilerini etkilemediği belirlendi. Bratis ve arkadaşları (2009) ile Saeidi ve arkadaşları (2020) çalışmalarında kadınların aleksitimi düzeylerinin erkeklere göre anlamlı şekilde yüksek olduğunu belirtmişlerdir. ${ }^{15,16}$ Literatürde yapılmış farklı çalışmalarda ise erkeklerde aleksitimi düzeyi kadınlara göre daha yüksek bulunmuştur. ${ }^{17,18}$ Toplumsal rollerinden ötürü erkeklerin duygularını paylaşmama eğiliminde olması ve hislerini ifade etme becerilerinin kadınlara göre daha sınırlı olması erkeklerin daha çok aleksitimik özellikler göstermesine neden olduğu düşünülebilir. Diğer yandan kadınların duygusal paylaşım ve iletişim becerilerinin yüksek olmasına karşın yaşamlarındaki olaylara yönelik tepkileri ve hisleri daha yoğun şekilde yaşaması, duygularını daha çok somatize etmesine neden olabilir. Çalışmamızda aleksitimi ile eğitim düzeyi arasında ilișki bulunmamasına karșın literatürde aleksitimiyi düşük eğitim düzeyi ile ilişkilendiren çalışmalar mevcuttur. ${ }^{2,19,20}$ Eğitim düzeyi arttıkça bireyin duygularını tanıma, anlama ve paylaşma konusunda daha bilgili olabileceği ve çevresiyle olan iletişiminde daha dışa dönük davranışlar sergileyebileceği düşünülebilir. Araştırmamızın sonuçlarından farklı olarak literatürde meslekte çalışma yılı arttıkça aleksitimi düzeyinin de arttığını gösteren çalışmalar bulunmaktadır. ${ }^{19,21} \quad \mathrm{Li}$ ve arkadaşları (2014) aleksitiminin hemşirelerin baş etme gücünü doğrudan etkilediğini, olumsuz başa çıkma nedeniyle sorunları çözmede daha çok stres yaşadıklarını ifade etmişlerdir. ${ }^{22}$ Her ne kadar severek tercih edilse de uzun yıllar çalışmanın getirdiği mesleki deformasyonlar ve iş stresi hemşirelerin aleksitimik özellik göstermesine neden olabilir. 
Tablo 1. Hemşirelerin tanımlayııı özelliklerine göre Toronto Aleksitimi Ölçeği (TAÖ-20) ve İletişim Becerileri Ölçeği- Yetişkin Formu (İBÖ-YF) puan ortalamaları

\begin{tabular}{|c|c|c|c|}
\hline \multirow{2}{*}{ Özellik } & \multicolumn{2}{|r|}{ TAÖ } & \multirow{2}{*}{$\begin{array}{l}\text { İBÖ-YF } \\
\text { Ort. } \pm \text { SS }\end{array}$} \\
\hline & $\mathbf{n}$ & Ort. \pm SS & \\
\hline \multicolumn{4}{|l|}{ Cinsiyet } \\
\hline Kadın & 74 & $52,73 \pm 6,82$ & $98,70 \pm 96,41$ \\
\hline \multirow[t]{2}{*}{ Erkek } & 27 & $53,52 \pm 6,50$ & $96,41 \pm 10,39$ \\
\hline & & $\mathrm{p}=0,604$ & $\mathrm{p}=0,293$ \\
\hline \multicolumn{4}{|l|}{ Medeni durum } \\
\hline Evli & 84 & $52,18 \pm 6,41$ & $98,63 \pm 10,01$ \\
\hline \multirow[t]{2}{*}{ Bekar } & 17 & $56,71 \pm 7,08$ & $95,41 \pm 7,39$ \\
\hline & & $\mathrm{p}=0,011$ & $\mathrm{p}=0,212$ \\
\hline \multicolumn{4}{|l|}{ Ĕgitim durumu } \\
\hline Sağlık meslek lisesia & 12 & $54,50 \pm 9,52$ & $98,17 \pm 6,90$ \\
\hline Önlisans ${ }^{\mathrm{b}}$ & 20 & $55,50 \pm 6,94$ & $92,90 \pm 6,37$ \\
\hline Üniversite $^{c}$ & 53 & $52,24 \pm 6,06$ & $98,68 \pm 10,33$ \\
\hline \multirow[t]{2}{*}{ Lisansüstü $^{\mathrm{d}}$} & 16 & $48,67 \pm 1,86$ & $109,00 \pm 5,36$ \\
\hline & & $\mathrm{p}=0,081$ & $\mathrm{p}=0,003(\mathrm{~d}>\mathrm{c}=\mathrm{b}=\mathrm{a})$ \\
\hline \multicolumn{4}{|l|}{ Sigara içme durumu } \\
\hline Evet & 21 & $54,14 \pm 9,64$ & $97,14 \pm 10,82$ \\
\hline \multirow[t]{2}{*}{ Hayır } & 80 & $52,63 \pm 5,75$ & $98,33 \pm 9,39$ \\
\hline & & $\mathrm{p}=0,359$ & $\mathrm{p}=0,634$ \\
\hline \multicolumn{4}{|c|}{ Kronik hastalık varlığı } \\
\hline Evet & 14 & $50,71 \pm 5,42$ & $101,71 \pm 7,91$ \\
\hline \multirow[t]{2}{*}{ Hayır } & 87 & $53,30 \pm 6,85$ & $97,51 \pm 9,83$ \\
\hline & & $\mathrm{p}=0,183$ & $\mathrm{p}=0,131$ \\
\hline \multicolumn{4}{|c|}{ Mesleği isteyerek seçme durumu } \\
\hline Evet & 74 & $52,74 \pm 7,44$ & $97,81 \pm 11,14$ \\
\hline \multirow[t]{2}{*}{ Hayır } & 27 & $52,74 \pm 6,47$ & $98,14 \pm 9,14$ \\
\hline & & $\mathrm{p}=0,627$ & $\mathrm{p}=0864$ \\
\hline \multicolumn{4}{|c|}{$\begin{array}{l}\text { İletişim becerileri eğitimi alma } \\
\text { durumu }\end{array}$} \\
\hline Evet & 31 & $48,38 \pm 10,28$ & $102,38 \pm 8,71$ \\
\hline \multirow[t]{2}{*}{ Hayır } & 70 & $55,51 \pm 7,32$ & $96,12 \pm 8,41$ \\
\hline & & $\mathrm{p}=0,008$ & $\mathrm{p}=0,029$ \\
\hline
\end{tabular}

Çalışmamızda medeni durumun aleksitimi düzeyini etkilediği; bekar hemşirelerde aleksitimi düzeyinin evlilere göre daha yüksek olduğu belirlendi. Kalaman, Orhan ve Kocabay' (2019) acil servis hemşireleriyle yürüttükleri çalışmanın sonuçları bizim çalışmamız ile paralellik göstermektedir. ${ }^{19}$ Bratis ve arkadaşlarının (2009) hemşirelerle yaptıkları çalışmada aile desteğinin aleksitimi düzeyini azaltmada yardımcı olduğu belirtilmiştir. ${ }^{15}$ Evli bireylerin aile üyeleriyle günlük yaşantı ve sorunlar hakkında paylaşımlarının olmasının ve iş dışındaki zamanlarda birlikte yapılan aktivitelerle daha çok sosyalleşebilmesinin aleksitimi düzeyini azaltmada katkı sağladığ1 düşünülmektedir.

$\mathrm{Bu}$ çalışmada, ameliyathane hemşirelerinin aleksitimi puan ortalamasının $52,94 \pm 6,71$ olduğu bulundu. Literatürde bizim çalışmamızla paralellik göstermekle birlikte orta derece aleksitimi sonucu bildiren çalışmalarda yer almaktadır. ${ }^{23-25}$ Hemşirelerin orta düzeyde aleksitimik oldukları ancak ekip anlayışının hakim olduğu ameliyathane ortamına göre aleksitimi düzeylerinin beklendik seviyede olmadı $\breve{g} 1$ söylenebilir. Çalışmamızda hemşirelerin aleksitimi 
puanları ile İBÖ puanları arasında istatistiksel olarak negatif yönde anlamlı bir ilişki olduğu belirlendi. Sancar ve Aktaş (2019) hemşirelik öğrencileriyle yaptıkları çalışmada benzer sonuçlar elde ederek aleksitimi ile iletişim becerileri arasında negatif yönde bir ilişki olduğunu bulmuşlardır. ${ }^{26}$ Hemşirelik mesleği bakım odaklı ve ekip anlayışı içerisinde yürütülen bir meslektir. Hemşirelerin aktif çalışma ortamı için hem hasta hem ekip üyeleri ile etkili bir iletişim sürdürmeleri gerekmektedir. $\mathrm{Bu}$ nedenle aleksitimik özellik gösteren hemşirelerin daha içe dönük davranışlar göstermesi ve duygularını ifade edememesinin iletişim güçlüğüne neden olduğu düşünülmektedir. Ayrıca ameliyathane hemşirelerinin ameliyat sırasında ekip ile iletişim halinde olma, sorunları çözebilme ve bakım sürecini yönetebilme becerilerinin aleksitiminin oluşturduğu duygusal anlamda içe kapanıklık ve somatize edilmiş fiziksel yakınmalardan olumsuz etkilenebileceği düşünülmektedir. Hemşirelerin hastalarla terapötik iletişim kurabilmesi ve ekip iletişimini etkili bir şekilde gerçekleştirebilmeleri için öncelikle kendi içindeki duygularla iletişim kurmaya ihtiyaçları vardır. Hemşirelerde iletişim becerilerinin güçlendirilmesi için ilk olarak duygusal farkındalıklarının arttırılması gerekmektedir. $\mathrm{Bu}$ durumun sonucu olarak kendi duygularını tanımaları ve bu duyguları ifade etmeleri ile iletişimin ilk adımını başlatmış olabilecekleri düşünülmektedir.

Tablo 2. Hemşirelerin bazı tanımlayıcı özellikleri, TAÖ ve İBÖ-YF puanları ve aralarındaki ilişki

\begin{tabular}{|c|c|c|c|c|c|c|c|}
\hline Özellik & $\begin{array}{r}\text { Puan } \\
\text { Ortalamaları }\end{array}$ & & & 2 & 3 & 4 & 5 \\
\hline (1)TAÖ & $52.94 \pm 6.71$ & & 1 & & & & \\
\hline \multirow[t]{2}{*}{ (2)ІंВÖ-YF } & $98.09 \pm 9.66$ & $\mathrm{r}$ & $-0,48$ & 1 & & & \\
\hline & & $\mathrm{p}$ & 0,04 & & & & \\
\hline \multirow[t]{2}{*}{ (3)Yaş } & $35.73 \pm 7.35$ & $\mathrm{r}$ & $-0,04$ & 0,08 & 1 & & \\
\hline & & $\mathrm{p}$ & 0,97 & 0,40 & & & \\
\hline \multirow[t]{2}{*}{ (4)Meslekte çalışma süresi } & $14.03 \pm 8.05$ & $\mathrm{r}$ & 0,03 & 0,03 & 0,89 & 1 & \\
\hline & & $\mathrm{p}$ & 0,74 & 0,74 & 0,00 & & \\
\hline \multirow[t]{2}{*}{ (5)Birimde çalışma süresi } & $10.50 \pm 7.84$ & $\mathrm{r}$ & 0,36 & 0,92 & 0,76 & 0,83 & 1 \\
\hline & & $\mathrm{p}$ & 0,74 & 0,41 & 0,00 & 0,00 & \\
\hline
\end{tabular}

\section{SONUÇ VE ÖNERILLER}

$\mathrm{Bu}$ çalıșmada ameliyathane hemşirelerinin orta düzeyde aleksitimik olduğu ve hemşirelerin aleksitimi düzeylerinin iletişim becerilerini olumsuz yönde etkilediği belirlenmiştir. Hemşirelerin duygusal farkındalığını arttıracak ve iletişim becerilerini güçlendirecek eğitim programlarının oluşturulması ve sosyalleşmelerini sağlayacak aktivitelerin düzenlenmesi önerilmektedir. Böylece hemşirelerin duygusal paylaşımlarının arttırılması hedeflenerek hastalarla ve ekip üyeleri ile etkili bir iletişimin sürdürülmesi sağlanabilir 


\section{KAYNAKLAR}

1. Şaşığlu, M, Gülol, Ç. ve Tosun, A. (2013). “Aleksitimi Kavramı”. Psikiyatride Güncel Yaklaşımlar, 5 (4), 507-527.

2. Batıün, A.D. ve Büyükșahin, A. (2008). "Aleksitimi: Psikolojik Belirtiler ve Bağlanma Stilleri”. Klinik Psikiyatri, 11, 105-114.

3. Hintistan, S. (2012). "Aleksitemi”. Gümüşhane Üniversitesi Sağlık Bilimleri Dergisi, 1 (4), 333-346.

4. Temiz, Z.T. (2018). "Bir Sınıflandırma Çalışması: Aleksitimik Belirtiler ve Bağlanma Örüntüleri”. Medeniyet Araştırmaları Dergisi, 3 (5), 21-42.

5. Gürkan, A. ve Ekitli, G.B. (2015). "Hemșirelik Sanatında Aleksitimi”. Türkiye Klinikleri J Psychiatr Nurs-Special Topics, 1 (1), 80-86.

6. Aksoy, M. ve Coban, G.İ. (2017). "Hemșirelik Öğrencilerinin Aleksitimi Düzeylerinin Bazı Değişkenler Açısından İncelenmesi”. Hemşirelikte Eğitim ve Araştırma Dergisi, 14 (1), 45-51.

7. Aslan, F.E. ve Öztürk, Z.K. (2011). "Güvenli Ameliyathane Ortamı; Biyolojik, Kimyasal, Fiziksel ve Psikososyal Riskler, Etkileri ve Önlemler". Maltepe Üniversitesi Hemşirelik Bilim ve Sanatı Dergisi, 4 (1), 133-140.

8. Ay, F, Polat, S. and Kashımı, T. (2020). "Relationship Between the Problem-Solving Skills and Empathy Skills of Operating Room Nurses". The Journal of Nursing Research, 28 (2), 1-10.

9. Yu, J. and Kirk, M. (2008). "Measurement of Empathy in Nursing Research: Systematic Review". Journal of Advanced Nursing, 64 (5), 440-454.

10. Happ, M.B, Garrett, K, Thomas, D.D, Tate, J, George, E, Houze, M, Radtke, J. and Sereika, S. (2011). "Nurse-Patient Communication Interactions in The Intensive Care Unit". American Journal of Critical Care, 20 (2), e28-40.

11. Kounenou, K, Aikaterini, K. and Georgia, K. (2011). "Nurses' Communication Skills: Exploring Their Relationship with Demographic Variables and Job Satisfaction in A Greek Sample". Procedia-Social and Behavioral Sciences, 30, 22302234.

12. Bagby, R.M, Parker, J.D.A. and Taylor, G. (1994). "The Twenty-Item Toronto Alexithymia Scale-I. Item Selection and Cross-Validation of The Factor Structure". Journal of Psychosomatic Research, 38 (1), 23-32.

13. Güleç, H, Köse, S. ve Yazıcı, M. (2009). "Yirmi Soruluk Toronto Aleksitimi Ölçeği'nin Türkçe Uyarlamasının Geçerlilik ve Güvenilirliğinin Incelenmesi”. Klinik Psiko Farmakoloji Bülteni, 19, 213-219.

14. Korkut-Owen, F. ve Bugay, A. (2014). "İletissim Becerileri Ölçeği’nin Geliştirilmesi: Geçerlik ve Güvenirlik Çalışması”. Mersin Üniversitesi Eğitim Fakültesi Dergisi, 10 (2), 51-64.

15. Bratis, D, Tselebis, A, Sikaras C, Moulou, A, Giotakis, K, Zoumakis, E. and Ilias, L. (2009). "Alexithymia and Its Association with Burnout, Depression and Family Support among Greek Nursing Staff'. Humon Resources for Health, 7 (72), 1-6

16. Saeidi, Z, Ebrahimi, H, Areshtanab, H.N, Tabrizi, F.J. and Mostafazadeh, A. (2020). "Alexithymia and Its Relationships with Job Burnout, Personality Traits, and Shift Work among Hospital Nurses: A Cross-Sectional Study". Nursing and Midwifery Studies, 83-89. doi: 10.4103/nms.nms_20_19

17. Honkalampi, K, Hintikka, J, Saarinen, P, Lehtonen, J. and Viinamaki, H. (2000). "Is Alexithymia A Permanent Feature In Depressed Patients?". Psychotherapy and Psychosomatics, 69, 303-308.
18. Yıldız, B ve Güllü, A (2018). "Belirsizliğe Tahammülsüzlük İle Aleksitimi Arasındaki İlişki ve Bazı Sosyodemografik Değişkenlere Göre Incelenmesi”. Adnan Menderes Üniversitesi Eğitim Fakültesi Eğitim Bilimleri Dergisi, 9 (1), 113-131.

19. Kalaman, S, Orhan, S. ve Kocabay, İ. (2019). "Sosyal Medya Kullanımı ve Aleksitimi: Acil Serviste Çalışan Hemşireler Üzerine Bir Arastırma". Online Academic Journal of Information Technology, 10 (37), 45-56.

20. Kirmayer, L.J. and Robbins, J.M. (1993). "Cognitive and Social Correlates of the Toronto Alexithymia Scale". Psychosomatics, 34 (1), 41-52.

21. De Vente, W, Kamphuis, J.H. and Emmelkamp, P.M.G. (2006). "Alexithymia, Risk Factor or Consequence of WorkRelated Stress?". Psychother Psychosom, 75, 304-311.

22. Li, S, Yao, G, Gui, Y. and Zhang, B. (2014). "Interrelation among Alexithymia and Negative Psychology of Nursing Personnel and Their Coping Style". Family Medicine and Community Health, 2 (2), 1-5.

23. Korkmaz, E.K, Telli, S, Kadıŏglu, H. ve Karaca, S. (2020). "Hemşirelerde Aleksitimi ve Aleksitiminin Tükenmişlik, Öfke ve Somatizasyon İle İlişkisi”. J Psy Nurs., 11 (4), 284-291

24. Shin, M.K. and Eom, J.Y. (2015). "Study on The Alexithymia and Anger in The Korean College Students". Advanced Science and Technology Letters, 116, 189-195.

25. Di Lorenzo, R, Venturelli, G, Spiga, G. and Ferri, P. (2019). "Emotional Intelligence, Empathy and Alexithymia: A CrossSectional Survey on Emotional Competence in a Group of Nursing Students". Acta Biomed for Health Professions, 90, (4), 32-43.

26. Sancar, B. and Aktaş, D. (2019). "The Relationship between Levels of Alexithymia and Communication Skills of Nursing Students”. Pak J Med Sci, 35 (2), 489-494. 